\title{
The European Union and Image Resilience during Times of Crisis: The Role of Public Diplomacy
}

\author{
Mai'a K. Davis Cross \\ College of Social Sciences and Humanities, Northeastern University, 1134 Tremont Street, Boston, \\ MA 02115, United States \\ m.cross@northeastern.edu \\ María Teresa La Porte \\ Faculty of Communication, University of Navarra, Social Science Building, University Campus, \\ 31080 Pamplona, Navarra, Spain \\ mtalfaro@unav.es
}

\begin{abstract}
Summary
A resilient actor is one with the capacity to recover from setbacks and obstacles, whether stemming from endogenous or exogenous factors. Beyond actual recovery, this article argues that there is also an important perceptional dimension. Image resilience is the capacity on the part of actors to overcome and deal with the widespread negative perceptions that often follow on the heels of these setbacks. The article argues that the ability to cultivate image resilience rests significantly on the power of public diplomacy. Through establishing a strong image for an actor over the longer term, public diplomacy enables that actor to be more resilient during times of crisis. The European Union is a particularly good case study to shed light on this. Using original interview evidence, this article examines a specific example of how the European Union was ultimately able to strengthen its image resilience in the United States through public diplomacy.
\end{abstract}

\section{Keywords}

European Union, public diplomacy, reliance, perception, crisis, image resilience, crisis-response strategy.

\section{Introduction}

Every actor in international relations - from governments to leaders to public or private institutions - faces crises and suffers from 'bad press' from time to time. Frequently, the media amplify and dramatize negative stories, emphasizing failures rather than successes in overcoming these problems. More recently, social media have even contributed to a stronger multiplier-effect, turning relatively small issues into seemingly insurmountable obstacles practically overnight. As a result, the external image of an actor may suffer from longer-lasting consequences than just the root source of the problem. Truly recovering from crises requires both survival and re-establishing a positive image. International actors thus strive for both resilience and image resilience.

The European Union (EU) is no exception. High-profile examples include the 2003 divisions in Europe over the Iraq crisis, the 2005 constitutional crisis and the 2010-2012 Eurozone crisis, among others. ${ }^{1}$ More recently, the migration crisis, ongoing struggles over Greek debt and numerous

\footnotetext{
${ }^{1}$ Mai'a K. Davis Cross and Xinru Ma, 'EU Crises and Integrational Panic: The Role of the Media', Journal of European Public Policy, vol. 22, no. 8 (2015), pp. 1053-1070.
} 
terrorist threats have sparked fresh criticism of how the EU has handled these challenges. It is perhaps no coincidence that the concept of resilience has garnered increasing attention in EU policy circles. ${ }^{2}$ Resilience is not about being able to prevent crises, but about being able to respond rapidly and effectively to them in order to restore stability. For example, the European Commission defines resilience as 'the ability of an individual, a household, a community, a country or a region to withstand, to adapt, and to quickly recover from stresses and shocks'. ${ }^{3}$ This definition is intended to articulate the EU's foreign policy in helping maintain the resilience of others, but, as we will discuss in this article, it could just as easily be applied to the EU itself.

A resilient actor is one with the capacity to recover from setbacks and obstacles, whether stemming from endogenous or exogenous factors. Beyond actual recovery, however, this article argues that there is also an important perceptional dimension. Image resilience is the capacity of actors to overcome and deal with the widespread negative perceptions that often follow on the heels of these stresses and shocks. ${ }^{4}$ The focus of this article is on this second dimension, although the two are, of course, closely related, as will be explained.

What do international actors do (or fail to do) to protect their image after responding to shocks and stresses? What is the goal of their response? And how effective is the EU at achieving image resilience? This article argues that the ability to cultivate image resilience rests significantly on the power of public diplomacy. Surprisingly, the growing literature on public diplomacy neglects the importance of image resilience. Instead, it tends to focus on an actor's image during a specific time period, but just like with soft power, the resilience of an actor's image over time is just as important as the strength of its image at any given point in time. Of course, there are many issues that shape the EU's image externally - good or bad policies, successful or failed execution of these policies, how the EU functions as an actor, and so on - but public diplomacy can be a useful tool in crafting positive narratives about these realities. By establishing a strong image for an actor over the longer term, public diplomacy enables that actor to be more resilient during times of crisis. This article aims to show how the various protective tools of public diplomacy can be operationalized.

The EU is a particularly good case study to shed light on the nature of image resilience and public diplomacy. Practically since its founding in 1957, the EU (or European Economic Community (EEC)/European Community (EC) in its previous incarnations) has been on a kind of image rollercoaster. At times, the EU is regarded in very positive terms, and widely recognized for its peaceful, cooperative and humanitarian role. At other times, it is portrayed as being in severe crisis, with its member states at loggerheads over the direction they would like European integration to go. There are serious misconceptions about the nature of the EU, but it is generally believed that the EU is a relatively successful experiment at large-scale and in-depth international cooperation when compared to similar endeavours in other regions of the world. The history of the EU demonstrates a singular capability to move forward whenever it runs into apparently irresolvable obstacles. Not only has the EU been able to overcome those obstacles (although it may not always fully resolve them), it has also maintained its gradual enlargement (from its six initial members to the current 28), its progress towards political and democratic goals (as the Treaty of Lisbon shows), and its unquestionable (although not always effective) commitment to promote international peace, to invest in development collaboration and to protect the environment globally. Thus, crafting a positive and resilient image of the EU abroad is both achievable and desirable, and it is clearly also necessary.

The article proceeds as follows. First, it elaborates upon the concept of image resilience, situating it in the literature on public diplomacy, and identifies three protective tools that are central to achieving such resilience. Second, it considers the Eurozone crisis as a significant case for the decline

\footnotetext{
${ }^{2}$ Volker Hauck, 'Resilience in EU International Cooperation: A New Fad?', Talking Points (Maastricht: European Centre for Development Planning Management, 12 October 2012), accessed at http://www.ecdpm-talkingpoints.org/resilience-ineu-international-cooperation-a-new-fad/.

3 European Commission, 'EU Approach to Resilience: Learning from Food Crises', Press Release, Memo (Brussels: European Commission, 3 October 2012).

${ }^{4}$ Mai'a K. Davis Cross, 'The Public Diplomacy Role of the EEAS: Crafting a Resilient Image for Europe', in David Spence and Jozef Bátora (eds), The European External Action Service: European Diplomacy Post-Westphalia (Houndmills: Palgrave, 2015), pp. 341-355.
} 
of the EU's image as a viable actor in the international system. Third, through original interview evidence, the article examines a specific example of how the EU was ultimately able to strengthen its image resilience through public diplomacy in the United States. Although the focus is on a single case study, it is a highly relevant and indicative example of the EU's protective tools more generally, as the United States was one of the principal critics of the EU during the Eurozone crisis (its negative views also had global influence), and the EU Delegation in Washington DC was entrusted with a leadership role in the EU's international efforts to repair its image. ${ }^{5}$ The article concludes by addressing how the EU has put protective tools into practice in order to build resiliency.

\section{Image Resilience and Public Diplomacy}

The concept of resilience has been broadly examined across multiple disciplines. It was first used in the engineering field as a unit to measure the capacity of materials to recover their original shape after an external impact. Since the 1960s, resilience has been applied to psychological experimental research, to evaluate the ability of an individual to recuperate from an adverse situation, ${ }^{6}$ and to sociology, to assess community resistance to catastrophic or humanitarian disasters. ${ }^{7}$ In the ecology literature, resilience is understood in two main ways: (1) 'the capacity to absorb shocks and still maintain function'; and (2) 'the capacity for renewal, re-organization and development'. ${ }^{8}$ In the psychology literature, an understanding of resilience is often based on the presence or absence of protective factors, which include: the ability to rebound, a sense of self, 'stick-to-it-iveness', and a pro-social (that is, amiable and benign) attitude. ${ }^{9}$

More recently, the concept has been used to understand organizational resiliency, specifically whether organizations are equipped to grapple with economic crises or situations of change. ${ }^{10}$ Scholars of organizational theory define resilience as the capacity to respond positively to a crisis or a critical situation through internal coping mechanisms — such as learning — to improve upon performance in the future. ${ }^{11}$ Resilience is not only a mechanism of resistance or survival, but also a means of evolving in the face of adversity. Given that the EU is a quasi-federal organization, this definition of resilience is most relevant to our approach.

To elaborate further, the Fundació Factor Humá finds that the existence of certain institutional resources can turn crises into positive learning experiences, and can create resilience over time. ${ }^{12}$ These resources are both tangible (such as capital or organization procedures) and intangible (such as values of creativity, proactive responses, and close collaboration of personnel within an

\footnotetext{
${ }^{5}$ Furthermore, we do not intend to advance generalized conclusions from the case study examined here, but to explain a thought-provoking example in depth. Single case-study methodology is most helpful when looking at in-depth explanations of social behaviour. As Bent Flyvbjerg asserts, 'a concrete, context-dependent knowledge is therefore more valuable than the vain search for predictive theories and universals'; see Bent Flyvbjerg, 'Five Misunderstandings about Case-Study Research', Qualitative Inquiry, vol. 12, no. 2 (April 2006), pp. 219-245. See also Fabio Luiz Mariotto, Pedro Pinto Zanni and Gustavo H. Salati, 'What is the Use of a Single-Case Study in Management Research?', Revista de Administração de Empresas, vol. 54, no. 4 (2014), pp. 358-369; and Zaidah Zainal, 'Case Study as a Research Method', Jurnal Kemanusiaan, no. 9 (June 2007).

${ }^{6}$ Michael Rutter, 'Resilience: Some Conceptual Considerations', Journal of Adolescent Health, vol. 14, no. 8 (1993), pp. 626-631; and Sandra Prince-Embury and Donald H. Saklofske (eds), Resilience in Children, Adolescents, and Adults: Translating Research into Practice (New York, NY: Springer, 2013).

7 Jeyanth K. Newport and Godfrey P. Jawahar, 'Community Participation and Public Awareness in Disaster Mitigation', Disaster Prevention and Management, vol. 12, no. 1 (2003), pp. 33-36; Brigit Maguire and Sophie Cartwright, Assessing a Community's Capacity to Manage Change: A Resilience Approach to Social Assessment (Canberra, ACT: Australian Government, Bureau of Rural Sciences, 2008); and Juan de Dios Uriarte Arciniega, 'La perspectiva comunitaria de la resiliencia', Psicología Política, no. 47 (2013), pp. 7-18.

${ }^{8}$ Carl Folke, 'Resilience: The Emergence of a Perspective for Social-Ecological Systems Analyses', Global Environmental Change, vol. 16, no. 3 (2006), pp. 253-267, quote from p. 253.

9 Janyce G. Dyer and Teena Minton McGuinness, 'Resilience: Analysis of the Concept', Archives of Psychiatric Nursing, vol. 10, no. 5 (1996), pp. 276-282, quote from p. 277.

${ }^{10}$ Lino Briguglio, Cordina Gordon, Nadia Farrugia and Stephanie Vella, 'Economic Vulnerability and Resilience: Concepts and Measurement', Oxford Development Studies, vol. 37, no. 3 (2008), pp. 229-247.

${ }^{11}$ Briguglio, Gordon, Farrugia and Vella, 'Economic Vulnerability and Resilience'.

${ }^{12}$ Fundació Factor Humà, 'La resiliencia en las organizaciones' (Barcelona: Fundació Factor Humá, 2010).
} 
organization).$^{13}$ In addition, if prior consensus exists on how to deal with crises through a process of ongoing dialogue and norms of flexibility among organizational members, resilience is likely to be higher. ${ }^{14}$ At the same time, most setbacks and shocks have both internal and external consequences for organizations. Our focus here is on the external consequences, which have a significant impact on an actor's reputation and public image.

Image resilience is clearly closely related to resilience. Resilience is the ability to overcome objective realities to ensure survival, and image resilience is about correcting subjective perceptions to restore reputation. Often, without the latter, the former cannot fully be achieved. For example, in the case of the 2010-2012 Eurozone crisis, as the EU took steps to deal with Greek debt, the perception grew and was amplified in the media that the crisis would not be confined only to Greece. A contagion effect ensued, in which international markets and rating agencies speculated that Greece's problems existed equally in other Eurozone countries. World markets bet against the survival of the currency as a whole, leading to a kind of self-fulfilling prophecy dynamic above the objective realities of the situation. ${ }^{15}$ Thus, resilience and image resilience can often be closely intertwined.

But where does image come from and what are the important explanatory factors in determining image resilience? As alluded to above, image is about external perceptions. At the same time, it is also grounded in the objective identity, values and policies of an actor. Since these objective qualities are often complex and multifaceted, especially for an organization like the EU, an actor's image, not unlike a photograph, is a 'representation' of what is really there. ${ }^{16}$ Because of this, diplomats engaged in public diplomacy can, and often do, play a role in constructing and solidifying the image of the actor they represent. There are, of course, many definitions of public diplomacy. Bruce Gregory defines it as 'instruments used by states, associations of states, and some sub-state and non-state actors to understand cultures, attitudes, and behaviour; build and manage relationships; and influence thoughts and mobilize actions to advance their interests and values. ${ }^{17}$ Public diplomacy is also sometimes thought of as how a nation's government or society projects itself to external audiences in ways that improve these foreign publics' perception of that nation. ${ }^{18}$ For example, the EU actively engages in public diplomacy to enhance mutual understanding, or to 'explain the EU' to external audiences. Yet, to be believable, these public diplomacy efforts must still be based on objective qualities of the actor, otherwise the actor will lack legitimacy and be unconvincing. It is widely understood that public diplomacy must be credible to be effective. ${ }^{19}$

The process of seeking to project a positive image to external audiences is thus the basis for building image resilience. What factors enhance image resilience? The expectation should be that the more protective tools that an international actor such as the EU has in its arsenal, the more likely it is that the actor will be able to maintain a resilient image. In the context of international relations, the responsibility of maintaining such protective tools naturally falls on the shoulders of diplomats and other external representatives. Public diplomacy therefore becomes a central factor in determining the resilience of an actor's image in international relations. In the long run, successful public diplomacy should result in augmented soft power and favourable policies towards the nation that engages in it.

Image resilience is thus fundamentally dependent on successful public diplomacy, as well as on concrete policies and other realities that can generate attractiveness and narratives about it. This in

\footnotetext{
${ }^{13}$ Juan Manuel Trujillo Torres, Juan Antonio López Núñez and Manuel Enrique Lorenzo Martín, 'Análisis y descripción de las percepciones de liderazgo resiliente y liderazgo distribuido en torno al ejercicio directivo (2.0)', Revista Iberoamericana sobre Calidad, Eficacia y Cambio en Educación, vol. 9, no. 3 (2011), pp. 14-29; Maguire and Cartwright, Assessing a Community's Capacity to Manage Change; and Arciniega, 'La perspectiva comunitaria de la resiliencia'.

${ }^{14}$ Torres, Núñez and Martín, 'Análisis y descripción de las percepciones de liderazgo resiliente y liderazgo distribuido en torno al ejercicio directivo (2.0)'.

${ }^{15}$ Mai'a K. Davis Cross, The Politics of Crisis in Europe (New York, NY: Cambridge University Press, 2017).

${ }^{16}$ Rune S. Andersen and Frank Möller, 'Engaging the Limits of Visibility: Photography, Security and Surveillance', Security Dialogue, vol. 44, no. 3 (2013), pp. 203-221, quote from p. 204.

${ }^{17}$ Bruce Gregory, 'Mapping Boundaries in Diplomacy's Public Dimension', The Hague Journal of Diplomacy, vol. 11, no. 1 (2015), pp. 1-25, quote from p. 8.

${ }_{18}$ Mai'a K. Davis Cross and Jan Melissen (eds), European Public Diplomacy: Soft Power at Work (New York, NY: Palgrave, 2013).

${ }^{19}$ Nicholas J. Cull, 'Public Diplomacy: Lessons from the Past', CPD Perspectives on Public Diplomacy (Los Angeles, CA: Figueroa Press, 2009).
} 
turn can lead to more soft power, which itself increases the likelihood that external societies will respond with favourable policies. What protective tools might an actor like the EU - as a supranational organization - have to ensure that its external image is resilient in the face of challenges? Synthesizing the literature on resilience discussed above, there are at least three main types of protective tools that are relevant to organizations like the EU. First, it stands to reason that there must be something positive and attractive about an international actor's policies, culture and identity in the first place. While it is not possible to be attractive to all target audiences, those audiences that an actor values most in its foreign affairs should ideally find these qualities attractive. This is the basis of soft power. ${ }^{20}$ Second, as the ecology literature suggests, the ability for an actor to reorganize or adapt to changing circumstances, especially shocks to the system, is crucial. Third, as the psychology literature stresses, a strong sense of pro-social identity should be cultivated that demonstrates the actor's resolve to pursue its goals and maintain its integrity. This may involve either emphasizing positive aspects of an actor's image while de-emphasizing threats to its image, or adjusting to any crisis or threat. At the individual level, this is analogous to a person who possesses self-esteem in the face of dissonance. ${ }^{21}$ On an organizational level, trustworthy leadership may be an essential condition, ${ }^{22}$ as well as the ability to communicate effectively externally. ${ }^{23}$ Over all, looking for the presence or absence of these protective tools captures most activities in which an actor such as the EU engages to bolster its image resilience, especially in that they capture both long-term imagebuilding and short-term reactions to crisis. There are probably other protective tools that are also relevant, depending on whether the actor is an international organization, state, network or other type of non-state actor. Future research could certainly break down these protective tools further, and add other components depending on the nature of the actor involved.

\section{The EU's Protective Tools}

In examining the first of the protective tools (that is, whether the EU has positive and attractive policies, culture and identity in the first place), it is clear that the EU has many attributes that outside audiences perceive to be attractive. EU foreign policies seek to promote international development, multilateralism, environmentalism, democracy, diplomacy and peace, while its internal policies pursue deeper integration, enlargement of membership, cooperation, the benefits of a common market, and so on. Indeed, these external policies are also the basis of the EU's normative power. ${ }^{24}$ While some EU member states occasionally face criticism for seemingly racist and xenophobic immigration policies, and the EU itself sometimes allows newer member states to water down EU democratic standards, the EU's culture overall seeks to protect diversity, inclusion, freedom of expression and minority rights. ${ }^{25}$ Its identity reflects long-term efforts to overcome past violence and division, among other things. The EU may be more or less successful at this at various times, but this is clearly the aim. As Steffen Bay Rasmussen argues, there have been two main sets of messages conveyed through EU public diplomacy: (1) the EU is internally diverse yet able to integrate successfully, making it a model for peace; and (2) the EU is an effective and legitimate external actor. ${ }^{26}$ These qualities - if communicated successfully — are sources of image resilience for the EU.

\footnotetext{
${ }^{20}$ Joseph Nye, Soft Power: The Means to Success in World Politics (New York, NY: PublicAffairs, 2005).

${ }^{21}$ Claude M. Steele, Steven J. Spencer and Michael Lynch. 'Self-Image Resilience and Dissonance: The Role of Affirmational Resources', Journal of Personality and Social Psychology, vol. 64, no. 6 (1993), pp. 885-896.

${ }^{22}$ Karina Nielsen and Fehmidah Munir, 'How Do Transformational Leaders Influence Followers' Affective Well-being? Exploring the Mediating Role of Self-efficacy', Work and Stress, vol. 23, no. 4 (2009), pp. 313-329.

${ }^{23}$ Fundació Factor Humà, 'La resiliencia en las organizaciones'.

${ }^{24}$ Ian Manners, 'Normative Power Europe: A Contradiction in Terms?', Journal of Common Market Studies, vol. 40, no. 2 (2002), pp. 235-258.

${ }^{25}$ Like all democratic actors, the EU and its member states struggle to find the 'right' balance when it comes to enforcing democratic standards. EU member states have their own individual democratic procedures, and it would thus be curious for the EU to impose changes that it deems objectively better from the outside without following processes that member states themselves deem legitimate.

${ }^{26}$ Steffen Bay Rasmussen, 'The Messages and Practices of the European Union's Public Diplomacy', The Hague Journal of Diplomacy, vol. 5, no. 3 (2010), pp. 169-180.
} 
The EU also has the infrastructure in place to project its policies and image to a wide audience. As Simon Duke points out, Brussels is the locus of one of the richest diplomatic communities in the world. 164 national missions and 36 international organizations are accredited to the EU. ${ }^{27}$ The many diplomats, public diplomats and other officials who populate this diplomatic community strive to achieve mutual understanding and have developed a sense of loyalty to the EU, even if they must sometimes debate controversial issues. Beyond Brussels, there is a strong presence of European diplomats in cities around the world. The approximately $140 \mathrm{EU}$ delegations, plus the member states' embassies and consulates, host a vast group of diplomats representing European values and foreign policies to a large audience.

The EU delegations around the world - all of which now have the status of embassies perform the bulk of the external public diplomacy outreach. In fact, somewhere between two-thirds and three-quarters of the EU's external communications budget has been allocated to EU delegations. ${ }^{28}$ Moreover, future shifts in budget - from internal to external aspects of public diplomacy - are likely as the budget and responsibilities of the European External Action Service (EEAS) grow. Before the 2009 Lisbon Treaty, the old European Commission delegations focused on media outreach, distribution of information and brochures, visitors programmes, internships, speaking tours and cultural events. Information sharing today, however, is gradually moving from a facts-based approach to a narrative, case-study approach. As Rasmussen argues, an emphasis on the latter will make it easier for the EU to link its actions to their positive effects and the EU's values of multilateralism, democracy and rule of law. ${ }^{29}$

Of course, like any political actor, the EU faces challenges in achieving these goals in practice. Arguably the single most difficult problem is that disagreements among EU member states and institutional in-fighting are often publicly visible. ${ }^{30}$ As Duke writes, the EU's public diplomacy:

$[\ldots]$ is about self-image, or the image that a given actor intends to project to a third party. The EU's PD [public diplomacy] is complicated by the imprecise nature of the EU's overall actorness or, put more simply, the type of actor the EU wishes to become on the international stage. This is in part due to the fact that the EU is an ongoing project, lacking finalité, but may also lie in a broader post-Cold War existential crisis about who and what the EU is on the global stage. ${ }^{31}$

Thus, considering the EU's potential to be an attractive actor that possesses soft power implies realization that its image is complex. The EU is a work in progress. It is often forgotten that internal dissonance in building a cooperative project such as the EU should be expected, given that the EU is comprised of democratic societies in which debate is normal and that there is respect for different viewpoints. Indeed, this is the case within any democratic entity.

In reacting to the EU's internal dissonance, however, the media often cast this democratic process of debate in a negative, harsh light. ${ }^{32}$ Thus, even though the EU as a whole very often takes common positions, speaks with one voice and achieves policy goals as a single actor, the harsh attention to the processes behind the scenes detracts from the image of the EU as a model for regional cooperation. Despite this, the numerous principles and values for which the EU stands are attractive attributes to most in the international system. EU diplomats spend much of their time and resources conveying these values and acting on these principles. They are charged with implementing related foreign policies and promoting mutual understanding when it comes to culture and identity. At base, when everything is business as usual, the EU has the ingredients for a strong image with a high level of soft power, fulfilling the criteria of the first protective tool - its policies, culture and identity are generally seen as positive attributes. The story is different, however, when it comes to the other

\footnotetext{
${ }^{27}$ Simon Duke, 'The European External Action Service and Public Diplomacy', in Mai'a K. Davis Cross and Jan Melissen (eds), European Public Diplomacy: Soft Power at Work (New York, NY: Palgrave, 2013).

${ }^{28}$ Rasmussen, 'The Messages and Practices of the European Union's Public Diplomacy', p. 274.

${ }^{29}$ Rasmussen, 'The Messages and Practices of the European Union's Public Diplomacy', p. 275.

${ }^{30}$ David Spence, 'The Early Days of the European External Action Service: A Practitioner's View', The Hague Journal of Diplomacy, vol. 7, no. 1 (2012), pp. 115-134.

${ }^{31}$ Duke, 'The European External Action Service and Public Diplomacy'.

${ }^{32}$ Cross and Ma, 'EU Crises and Integrational Panic'.
} 
protective tools and times of crisis. While the first protective tool rests on an actor's image over time, the second and third protective tools - the ability to adapt to changing circumstances and to project a pro-social identity in the face of adversity - are only visible in reaction to actual crises. The second and third protective tools will be discussed in the next section, using the Eurozone crisis as a case study.

\section{The Case of the Eurozone Crisis}

To test for the presence or absence of the second and third protective tools in examining the case of the Eurozone crisis, we now ask the following questions. Does the EU possess the ability to adapt as circumstances change during a crisis (the second protective tool)? And is the EU able to project a general sense of confidence or perseverance in achieving collective goals, emphasizing its positive actions, even when confronted with adversity (the third protective tool)? If EU leaders or representatives are able to articulate the collective European commitment to integration, correct misperceptions and effectively explain crisis responses in a positive way - even if this requires adaptation to circumstances in the midst of crisis - then there is evidence for these protective tools. The case of the Eurozone crisis and how the EU responded to this through public diplomacy in the United States enables us to evaluate one key aspect of the EU's image resilience in response to this significant challenge to its stability.

Even though the 2010-2012 Eurozone crisis had clear origins in the 2008 Wall Street subprime mortgage collapse, the EU itself lost credibility during this period, and was suddenly seen as a weak player in the world. The euro currency had been second only to the dollar immediately before the crisis, but in a matter of months, it was quickly being portrayed as on the verge of breakdown. The denigration of Europe's image was especially visible in statements coming out of influential American political and economic institutions, as well as among groups of experts, whose critical ideas were trumpeted in the mainstream media.

The EU Delegation to the United States strived intensively to offset a growing and negative narrative about the European Union. EU diplomats tried to make the most of the situation, pursuing a wide range of strategies: from giving profound and comprehensive explanations of the European project and its benefits to the global economy, to detailing new policies that the EU and its state members were implementing to redress imbalances and to prevent future disruptions. Thus, according to the conditions set in our protective-tools framework, the overall reaction of the EU Delegation in Washington DC demonstrates a significant effort to achieve image resiliency through using the second and third protective tools described (that is, adaptation and perseverance). This section of the article analyses the EU Delegation's public diplomacy strategies to counteract negative perceptions in the United States, through in-depth semi-structured interviews conducted with diplomatic practitioners located in Washington DC.

\section{Background}

The Eurozone crisis deeply shook the foundations of the EU, provoking open division among the members' economic policy positions. Financial fragmentation, dramatic increases in unemployment across southern Europe, overall economic decline and currency depreciation presented a huge challenge for the EU's internal and external functioning. The media, most prominently sceptical American and British sources, contributed to spreading negative predictions about the crisis, underestimating the patent solidarity among EU member states, and amplifying a sense of integrational panic. ${ }^{33}$ Journalists tended to ignore outright the significant and painful efforts that the EU was making to adjust its economic structures, policies and system of financial governance. As a result, the EU had to deal with both economic and image (prestige and reputation) recovery.

The United States is naturally of major importance to the EU. Beyond the traditional transatlantic security alliance, cultural similarities and joint research and development (R\&D)

\footnotetext{
${ }^{33}$ Cross and Ma, 'EU Crises and Integrational Panic'.
} 
projects, the United States is the main market for European companies. The EU and the United States are each other's main trade partners: foreign direct investment (FDI) ties are US\$ 1.8 trillion every year and foreign trade between the two of them amounts to US\$ 1 billion a day ( $€ 411$ billion). The EU and United States account for 20 per cent of each other's exports in products, ${ }^{34}$ and 30 per cent of each other's exports in services. Together, their economies make up 50 per cent of global Gross Domestic Product (GDP). In 2007, the Transatlantic Economic Council was created with the objective of overseeing closer integration between the economies of the EU and United States. ${ }^{35}$ Despite discordant negotiations, strong efforts have been made to sign a Transatlantic Trade and Investment Partnership (TTIP), which would bring the two even closer together.

Since the beginning of the European economic crisis, American public opinion was dominated by a negative interpretation, which blamed the EU as the sole culprit. In other words, many in the United States believed that the crisis in Europe did not originate from the American collapse of 2008, but was a consequence of erroneous economic policies, structures and mechanisms. They assumed that recovery would imply either complete reform of the EU, or the dissolution of the institution.

There were numerous causes for this skewed interpretation: many US academics in the field of economics held pessimistic views on European Monetary Union; ${ }^{36}$ there was an immediate impact in the US political debate (liberals versus non-liberals regarding Obama's social policies); and the US media hammered home negative portrayals, often relying on euro-sceptical British sources, especially concerning the southern European states. ${ }^{37}$ Such perceptions led many in the US political and business sectors to regard the EU project as discredited. Moreover, there was also an increasing fear that the European crisis could pull down the US economy again, slowing its recovery and, ultimately, affecting global growth.

The EU reacted from the start of the crisis, demonstrating its resolve to both adapt and persevere. The EU's first Ambassador to the United States from 2010-2014, ${ }^{38}$ João Vale de Almeida, and the Principal Advisor for Economic and Financial Affairs at the Delegation of the EU to the United States, Antonio de Lecea, were the main European representatives based in Washington DC dealing with the crisis. They were supported by the staff of the EU Delegation in Washington DC, ${ }^{39}$ and were complemented by officials in Brussels, who were also dealing directly with the US administration. ${ }^{40}$ However, it was clearly de Lecea and Vale de Almeida who served as the official 'faces' of the EU for people in the United States who were interested in understanding the Eurozone crisis.

Minister Antonio de Lecea, ${ }^{41}$ who had been sent to Washington DC at the end of 2009 to deal with the G20 and other international economic institutions, immediately focused on coordinating the

\footnotetext{
${ }^{34}$ See http://en.reingex.com/Course-Foreign-Trade-Management.shtml.

${ }^{35}$ EEIN Business School, 2014.

${ }^{36}$ Inspired by Rudiger Dornbusch's classification of US commentators on the euro as falling into three 'camps', which he described with the following three arguments: It can't happen; It's a bad idea; and It can't last. See Rudiger Dornbusch, 'The Euro Controversy', Editorial, MIT Department of Economics (2001), as cited in Lars Jonung and Eoin Drea, 'The euro: It Can't Happen. It's a Bad Idea. It Won't Last. US Economists on the EMU, 1989-2002', Economic Papers 395 (December 2009), prepared for the session 'Reflections on American Views of the Euro Ex Ante: What We Have Learnt 10 years Ex Post', at the 10:15am AEA meeting, San Francisco, 3 January 2009.

${ }^{37}$ Interview with Minister Antonio de Lecea, Washington DC, 4 November 2014.

${ }^{38}$ Ambassador João Vale de Almeida had professional experience in public communication as a former journalist who had served as an EU Commission press spokesman.

${ }^{39}$ Specifically, they worked on a daily basis with the Communication Department of the EU Delegation, following media content and considering possible reactions.

40 The EU crisis could affect directly the American as well as the global economic situation. Representatives of the EU in Brussels were in close contact with the US administration, the Treasury Secretary and the International Monetary Fund (IMF), which is part of the 'Troika'.

${ }^{41}$ Antonio de Lecea was appointed as Principal Advisor for Economic and Financial Affairs at the EU Delegation to the United States in October 2009. Prior to joining the EU Delegation, de Lecea served as the Director for International Affairs in the European Commission's Directorate-General for Economic and Financial Affairs, steering analytical and policy support for the Commission's economic relations with non-EU countries and multilateral and regional economic institutions, including the IMF, the World Bank, the G20, the G7/G8 and the Organization for Economic Cooperation and Development (OECD).
} 
public diplomacy campaign to manage the crisis, which had just begun. This was also the case for Ambassador João Vale de Almeida ${ }^{42}$ who, not by chance, arrived in the United States early in 2010.

The EU Delegation and the EU member states acted largely independently of each other. Although Ambassador Vale de Almeida and Minister de Lecea held regular meetings with the European embassies located in Washington DC to keep each other informed, the European states faced the consequences of the crisis in their countries separately and developed different public diplomacy strategies. ${ }^{43}$ Later, these positions gradually converged, showing the presence of the second protective tool - the ability to adapt to circumstances as they evolved.

Although all the EU staff tried to respond starting from the outbreak of the crisis, they became more active in 2011, when the first EU crisis-response measures began to show initially positive results. The period from 2012-2014 was the ideal time to understand the main causes of the crisis, to evaluate the consequences in different sectors and countries, and to differentiate between superficial statements and real facts. In line with the third protective tool, it was also the time to demonstrate the gradual effectiveness of the EU's policies, not only in the European sphere, but also in the United States and global markets. ${ }^{44}$

\section{EU Public Diplomacy in Washington DC, 2011-2014}

The EU Delegation's approach followed the steps that are generally taken by any strategic communication action: identification of the objective; development of a master strategy; articulation of specific actions; refinement in the content of the messages; and consideration of target audiences. As described below, these steps provided a basis for the second and third protective tools.

The main objective of the EU Delegation was to influence American perceptions of the Eurozone crisis by conveying a different argument than those commonly believed in the United States at the time. The goal was to persuade others to consider the EU to be a reasonable actor, and one that was reacting responsibly to the growing economic turmoil. ${ }^{45}$ This included providing a detailed description of the measures that the EU was taking to resolve the crisis, clarifying misunderstandings generated by experts and propagated by the media, correcting inaccurate polls and countering hasty official statements. These strategies were indicative of adaptation, perseverance and a pro-social approach, as discussed in this article's framework.

When defining the EU Delegation's master strategy, a prior approach for tackling the crisis was decided among the EU staff: to relate consistently the EU's understanding to the American comprehension in order to reduce bias and to induce an open attitude of listening. This delicate balance required trying to carve out common ground between these two major, conflicting perspectives. To achieve this purpose, two simultaneous tactics were developed.

On the one hand, public diplomacy experts adopted an auto-critical frame. Despite Brussels' objections, and according to a general American expert's understanding, both Ambassador Vale de Almeida and Minister de Lecea pointed out that the crisis was not only generated in the United States, but that the EU also had structural problems and malfunctions that had not been addressed quickly enough. Indeed, those problems had played a role in worsening the economic crisis. The delegation

\footnotetext{
42 Ambassador João Vale de Almeida (Portugal) led the EU Delegation to the United States from 2010 to 2014. Ambassador Vale de Almeida was the first EU Ambassador to the United States since the Treaty of Lisbon came into force in December 2009. The Treaty's new institutional set-up has empowered the EU to speak with one voice and to play its full part on the global stage. Current EU Ambassadors represent the Presidents of the European Commission and the European Council, under the authority of the High Representative for Foreign Affairs and Security Policy.

${ }^{43}$ For instance, Spain expressly wanted to underscore the differences between the Spanish crisis and the Greek situation; interview with Spanish Ambassador Ramón Gil-Casares, Washington DC, 13 August 2014. Disputes also sometimes arose between Greece and Germany, and the United Kingdom manifested suspicion of the leading role that the EU Ambassador was playing during the crisis; see James Kirkup and Robert Winnett, 'New EU Ambassador in Washington Claims Transatlantic Authority', The Telegraph, 12 August 2010, available online at http://www.telegraph.co.uk/news/worldnews/europe/eu/7941313/New-EU-ambassador-in-Washington-claims-transatlanticauthority.html.

${ }^{44}$ Antonio de Lecea, 'The Euro Area Crisis: Getting the Model Right', opening keynote address, conference on 'A Global Perspective of the European Crisis', University of North Carolina, Chapel Hill, NC, 18 September 2014.

${ }^{45}$ Interview with Minister Antonio de Lecea, Washington DC, 4 November 2014.
} 
expected that this self-recognition of deficiencies would improve the credibility of European representatives with respect to some American audiences, and would foster a willingness to listen.

On the other hand, using the third protective tool, public diplomacy experts researched the academic underpinnings of the American understanding of the economy. Using a pro-social approach, they learned to frame properly their explanations of EU initiatives in the language of American economic theory. Besides facilitating the dialogue with the US experts and improving their understanding of EU policies, knowledge of US economic theory enabled the EU representatives to try to move the focus of the discussion from enormous mistrust in the future of the European project to the more traditional dispute between opposing American and European economic views: the US assumption that 'austerity was going to curtail growth' versus the European assumption that 'there was no opposition between austerity and growth'. ${ }^{46}$

In order to achieve those goals, the actions that were developed had a main line: to make the European position visible by taking the initiative; actively speaking with opinion leaders; and engaging in dialogue with the more influential publics, no matter how critical they were. All of this indicated the use of both the second and third protective tools: adapting to circumstances; and adopting a pro-social identity in the face of conflict. This particularly included not waiting passively at the delegation's headquarters and expecting the media and think tanks to come to them. As Minister de Lecea asserted, 'they knocked at the doors and asked to be listened' by appealing to the American high-valued principle of objectivity and honesty: 'You do not have to agree with me. But, if you do not listen to me, you will only have one perspective on the crisis and will miss the full picture. It hinders you making a correct decision' ${ }^{47}$ This pro-social attitude was always respectful, but remained firm. Although they also tried to compete with media information providing updated material immediately after any meeting of the European Council, the strategy prioritized a more contained discourse, where the complexity of the situation could be explained and the EU measures could be properly defended. ${ }^{48}$

The EU Delegation's approach demonstrates not only a strategic way of addressing a critical attitude, but also a sincere attempt to launch a real dialogue based on a common background. This was a point at which all three protective tools converged, emphasizing the long-term soft power relationship of the two actors, the ability to adapt to circumstances, and a positive, pro-social identity, despite adversity.

But the crucial piece of the EU's public diplomacy action was the content of the official narrative. It included some basic key ideas that had been elaborated following the aims identified above. Arguments were put forward in parallel to the evolution of the crisis, and were phased out as needed. The language used was designed to simplify complexity, but also to be precise, comprehensible and graphic. ${ }^{49}$ It should also be stressed that the focus was on elaborating narratives instead of facts-based arguments, as Rasmussen suggests. ${ }^{50}$

The EU Delegation's official discourse was broken down into four main ideas: first, to clarify the complexity of the Eurozone crisis with a detailed and coherent explanation (providing a comprehensive analysis); second, to facilitate information about the positive effects of EU measures to ameliorate problems; third, to put the crisis into context, jogging memories of EU successes in the past, the benefits of belonging to the Eurozone, and highlighting the visible signals of solidarity with which EU member states were facing the situation; and, fourth, to maintain a global perspective of the economic crisis.

By showing an understanding of the complexity of the Eurozone crisis, EU representatives demonstrated a potential capacity to confront it properly — that is, as the second protective tool affirms, an ability to adapt to changing circumstances. The complexity of the Eurozone crisis was described by examining the confluence of different factors that were aggravating the situation and hindering a rapid recovery. The EU representatives called it 'A Perfect Storm' (a clever and understandable metaphor), which was created through different elements: an unsustainable European

\footnotetext{
${ }^{46}$ Ambassador Vale de Almeida in PBS Newshour, 'After Second Bailout, is Greece Still Likely to Default?', available online at http://www.euintheus.org/press-media/pbs-newshour-after-second-bailout-is-greece-still-likely-to-default/.

${ }^{47}$ Interview with Minister Antonio de Lecea, Washington DC, 4 November 2014.

${ }^{48}$ Interview with Minister Antonio de Lecea, Washington DC, 4 November 2014.

${ }^{49}$ Metaphors were used profusely, with the most salient being the comparison with a storm.

${ }^{50}$ Rasmussen, 'The Messages and Practices of the European Union's Public Diplomacy', p. 274.
} 
fiscal policy (discipline was not strong enough); lack of competitiveness (losses in competitiveness in southern European countries were not tackled early enough); a financial storm (the financial sector had mispriced risk, leading to a misallocation of capital, excessive borrowing and the creation of bubbles); and incomplete economic governance. ${ }^{51}$ Most of these arguments were shared by the US experts, and the fact that the EU was able to diagnose and face the problems could be seen as a sign of honesty and realistic assessment of the situation. In turn, this overt display of EU expertise helped to build the American experts' trust in the EU's ability to grapple with the crisis.

In that sense, there was also a parallel effort to explain the intricacies of EU decision-making processes. As Ambassador Vale de Almeida repeated on several occasions, 'You have to understand that when people sort of criticize the European Union for being slow and complex, we are not a country. We are 27 countries very diverse that require discussion so that we get to consensuses' ${ }^{52} \mathrm{~A}$ defence of EU goals and integrity, especially maintaining the principle of 'united in diversity', reflected a commitment to the European project and use of the third protective tool.

In terms of the second idea (namely, spreading information about the positive effects of EU measures), by 2012 and 2013, European actions to manage the crisis had obtained their first positive results. The EU Delegation in Washington DC amplified them by highlighting those outcomes that could most impress the American public: economic growth; unemployment reduction; improved confidence; activity in the construction sector; increased volume of retail trade; and competitiveness (all strengthening the EU's protective tools). They were presented as 'Signs of Turnaround'. And a detailed analysis of the improvements was provided to counteract media simplifications and misinterpretation. Graphs, statistics and figures were used to show the evolution of the crisis in many of the presentations. Rigorous data attempted to eliminate the main prejudices that had become generalized among US experts. As Minister de Lecea concluded in one of his lectures, echoing Fred Bergsten's thesis, the '5 Myths About the Euro Crisis' never happened:

The Europeans are getting their act together; the Greek exit has not occurred; German (and other Member State) taxpayers are showing solidarity coupled with responsibility; voters in the debtor countries are making strenuous efforts and are largely skeptical of siren songs; the euro crisis will not tank the world economy. ${ }^{53}$

Although optimistic perspectives were moderated by pointing out challenges that the EU still had to address (including progress in institutional framework, countries' adjustment strategies and youth unemployment, among others), the European delegates stressed the idea that 'the worst of the crisis is behind us' and that Europe was solving its problems and was 'becoming part of the solution', working together with the United States 'in recreating the G20 to respond to the global financial crisis and reform the global economic governance to prevent future crises' ${ }^{54}$

The third idea of the official discourse was congruent with the aims of the first protective tool. The aim was to remind everyone of the EU's successful history over the last 50 years. EU representatives thus drew public attention to the significant achievements accomplished by the European growth model, the 'convergence machine' that had also benefited developing countries and the solidarity and commitment shown by EU member states during the Eurozone crisis, specifically towards Greece. ${ }^{55}$ These EU officials also emphasized that the Eurozone was providing significant advantages to its members despite the current situation and that 'the Economic and Monetary Union

\footnotetext{
${ }^{51}$ Antonio de Lecea, 'Keynote Address', Symposium on Building the Financial System of the $21^{\text {st }}$ Century: An Agenda for Europe and the US, Harvard Law School, 22 March 2012.

52 Ambassador Vale de Almeida in PBS Newshour, 'Will Europe's Debt Deal Calm Fears of Prolonged Recessions?', 21 February 2012, available online at http://www.pbs.org/newshour/bb/business-july-dec11-eurozone2_10-27/.

${ }^{53}$ Antonio de Lecea 'The Euro Area Crisis and European Integration', University of Maryland, 31 January 2013.

${ }^{54}$ De Lecea, 'The Euro Area Crisis: Getting the Model Right', opening keynote address, conference on 'A Global Perspective of the European Crisis', University of North Carolina, Chapel Hill, NC, 18 September 2014.

55 'I think we're talking about a situation in which one needs to find the right balance - balance between solidarity and responsibility. Solidarity is what Europe is showing, together with the IMF, towards a country in difficulty'; Ambassador Vale de Almeida in PBS Newshour: 'After Second Bailout, is Greece Still Likely to Default?', available online at http://www.euintheus.org/press-media/pbs-newshour-after-second-bailout-is-greece-still-likely-to-default/.
} 
was a catalyst of economic and political integration as well as a symbol of identity' ${ }^{56}$ The awarding of the 2012 Nobel Peace Prize to the European Union provided significant reinforcement of this idea, especially in evoking the EU's successful track record in dealing with troubled times. ${ }^{57}$

Together with that effort to remind the public of the positive European contribution to resolving the crisis, Ambassador Vale de Almeida strived to cope with the 'bad' EU image by broadening the picture in which the crisis was taking place. This was the fourth main idea of the EU Delegation's planned content. He asserted:

In my speeches, I always try to stress the importance of having a global perspective. If we understand the world better, we will understand the local environments better. This is because we live in an interconnected world. So, having the big picture in mind will help bring about win-win solutions to problems that sometime seem impossible to handle..$^{58}$

As well as this, since 2013, the ambassador drew the public's attention to the launch of the TTIP negotiations, arguing that it would generate significant benefits both for the United States and the EU, and would be 'an agreement among equals', also noting that 'these [the United States and the EU] are the two most important economic blocks in the world' ${ }^{59}$ Maintaining this global perspective, Vale de Almeida stressed that the TTIP agreement would allow North Atlantic economies to compete securely with new emerging markets. In doing so, he multiplied his public appearances, granting media interviews, giving speeches to selected audiences and even posting entries in the Huffington Post. ${ }^{60}$

Regarding the selection of publics, the criterion was to tackle those groups of experts that had power to influence the decision-making process, and yet could also be negatively swayed by media rhetoric and imprecise information. ${ }^{61}$ The EU Delegation visited and addressed prestigious think tanks (for example, the Peterson Institute, ${ }^{62}$ the Brookings Institution and the Council on Foreign Relations), financial experts, banks' research departments, evaluation agencies, representatives from embassies of G20 members, and universities (especially those with European Studies Departments, such as the Harvard Center for European Studies). Although reaction to breaking news was not a priority, holding meetings with mainstream media editorial boards was a specific strategy (for example, Ambassador Vale de Almeida met journalists from the Boston Globe).

Vale de Almeida and de Lecea also visited many states outside of the District of Columbia Kansas, Missouri, West Virginia, Minnesota, South Dakota and Nebraska - to meet with government officials, college professors, students and business communities. They explained the crisis to these audiences, defended the recovery process, and adjusted discussions to specific local needs and interests. ${ }^{63}$ At the end of his stay in Washington DC, Ambassador Vale de Almeida could boast that he had visited all 50 US states, and had the opportunity to talk with a wide range of local authorities, including mayors, governors and senators. ${ }^{64}$ Although a reception with the President of the United States or with members of the US Congress is part of any international organization's representation programme in Washington DC, for the new EU Delegation, this took on added value and became part

\footnotetext{
${ }^{56}$ Antonio de Lecea, 'Keynote Address', Symposium on Building the Financial System of the 21st Century: An Agenda For Europe and the US, Harvard Law School, 22 March 2012.

${ }^{57}$ See Vale de Almeida's post in The Huffington Post, 'Celebrating Europe's Peace and Unity', 9 May 2013.

${ }^{58}$ C. Naseer Ahmad, Interview of João Vale de Almeida, European Union Ambassador to the United States, 5 December 2014, available online at http://www.euintheus.org/press-media/pbs-newshour-after-second-bailout-is-greece-still-likely-todefault/.

59 Ambassador Vale de Almeida quoted in Kenny Kemp, 'EU Envoy Promotes Trade Pact', Charleston Gazette-Mail (Charleston, WV, April 2014).

${ }^{60}$ Among others, from September to December 2013, Vale de Almeida was interviewed several times by PBS, by the Center for European Analysis, he went to Indiana University, to the European/American Chamber of Commerce and posted entries in The Huffington Post with significant titles: 'Building the Largest Free Trade Zone in the World' (17 June 2013); and 'EUUS Trade Talks Should Top Our 2014 To-Do List' (20 December 2013).

${ }^{61}$ Brussels interacted directly with the US administration; therefore the EU Delegation could focus its efforts on other audiences.

62 Ambassador Vale de Almeida gave a comprehensive lecture on 'European Sovereign Debt: Insights into the Crisis, the Response, and New Opportunities' on 17 September 2010.

${ }^{63}$ See the EU Delegation in the US website: Ambassador's Corner, available online at http://www.euintheus.org/who-weare/ambassadors-corner/.

${ }^{64}$ C. Naseer Ahmad. Interview of João Vale de Almeida.
} 
of its meaningful impact vis-à-vis the Eurozone crisis. ${ }^{65}$ Prioritizing interested audiences (academic and business communities) allowed the delegation not only to deliver the kind of complete and detailed discourse necessary to explain fully what was happening, but furthermore established first contacts with publics that were more open to engagement and to maintaining a durable relationship.

Some of the noteworthy lessons learnt from that experience, according to de Lecea, could aptly sum up the public diplomacy strategy followed by the EU Delegation: address complex issues; discuss profound ideas; and elaborate upon a political discourse that is not dominated by media distortions.

\section{Impact of the EU Delegation}

While a more comprehensive study of all the dimensions of EU public diplomacy to promote image resilience during the Eurozone crisis is beyond the scope of a single article, it is noteworthy that the EU's image in the United States did improve towards the end of the period of study. For example, in 2014, 53 per cent of Americans were favourable to the negotiation and approval of the TTIP and only 20 per cent were against it. ${ }^{66}$ Expert opinion experienced a significant change as well. As Peter Sparding, from the Aspen Institute, recognized in 2015, despite a continued sceptical and cautious outlook:

Europe has long been - and remains - the most important economic partner and top destination for US foreign investments. [...] In 2012, roughly $60 \%$ of Corporate America's total foreign assets were in Europe. Europe also accounted for $48 \%$ of the aggregate global output of US affiliates in the same year. And there were strong signs that US investments would continue to play a major role in Europe going forward. For example, several reports indicated that US venture capital investors were steadily increasing their share of early-stage startup funding in Europe, accounting for as much as $10 \%$ of such funding in $2013 .{ }^{67}$

Of course, these shifts in perceptions were also the result of several factors related to an ongoing process of solving the root causes of the Eurozone crisis. As this article has argued, resilience and image resilience are firmly intertwined. Thus, the extent to which the EU Delegation's campaign specifically contributed to restoring US perceptions of the EU cannot be separated from the overall economic recovery. However, it can be maintained that many of the conditions necessary to build a resilient image for the EU were present in the EU Delegation's strategy, and should be continued in order to consolidate this progress. At the same time, it is also clear that despite the presence of this strategic public diplomacy effort in Washington DC, the EU still suffered from a lingering decline in its reputation worldwide as a result of the Eurozone crisis.

\section{Conclusion}

This article has defined image resilience as the capacity on the part of actors to overcome and deal with widespread negative perceptions that follow a crisis. It has argued that the conditions (protective tools) necessary to foster image resilience in an organization are: (1) policies, culture and identity that others find to be attractive in the first place - that is, the basis of soft power; (2) the ability of an actor to reorganize or adapt to changing circumstances, especially shocks to the system; and (3) a strong sense of pro-social identity, with the resolve to pursue goals and maintain integrity. While the first protective tool can be cultivated over the longer term, the second and third are found in the capacity of an organization to respond to crises, such as having the tools to emphasize positive aspects

\footnotetext{
${ }^{65}$ Ambassador Vale de Almeida presented his credentials to US President Obama in 2010, and the EU Delegation organized a reception for the members of the $113^{\text {th }}$ US Congress on Capitol Hill on 14 February 2013.

${ }^{66}$ See http://www.pewglobal.org/2014/04/09/support-in-principle-for-u-s-eu-trade-pact/. See also analysis provided by the German Marshall Fund on energy cooperation: http://www.gmfus.org/blog/2015/10/08/ttip-presents-opportunity-us-euenergy-cooperation.

67 Peter Spanding, 'America's Views of Europe's Economic Outlook' (3 February 2015), available online at http://www.aspeninstitute.it/aspenia-online/article/america\%E2\%80\%99s-views-europe\%E2\%80\%99s-economic-outlook.
} 
while de-emphasizing threats to an actor's image, or adjusting to any crisis or threat. It goes without saying that leadership and the ability to communicate effectively provide the basis for developing these tools.

With respect to these protective tools, the article has analysed the public diplomacy strategies that the EU Delegation to the United States developed and executed to counteract the consequences of the Eurozone crisis. Through in-depth interviews and narrative analysis of the two main EU actors in the United States, the article reconstructed the EU's 'image resilient strategy' in this particular case. The analysis shows that the aim was not only to defend the EU as an effective institution that is able to grapple with crisis, but to present it as part of the solution and an indispensable factor in reactivating the global economy. The three protective tools identified earlier were present throughout the communication campaign, and were often employed simultaneously.

Concerning the first protective tool - that is, to stress positive and attractive values for a target audience - we observed that the EU Delegation manifested them by means of attitudes, behaviours and narratives. Europe's long-term principles and historical achievements were also highlighted as part of the official discourse, including receipt of the Nobel Peace Prize in 2012. Commitment, seriousness, openness to dialogue, self-recognition of weaknesses, honesty and solidarity with those impacted by the crisis were expressed throughout the leadership of Ambassador Vale de Almeida and Minister de Lecea. Concerning the second protective tool, the EU Delegation had understood the relevance of stressing those European attitudes that were most closely aligned with American values. The public diplomacy strategy demonstrated that Vale de Almeida and de Lecea were clearly aware of the cultural idiosyncrasies of their target audience, and thus made frequent allusions to the viewpoints of leading US opinion-shapers and to American ideas on economic governance. Among other things, they explained the effectiveness and coherence of the policies enforced by the EU to deal with the crisis; highlighted the notable solidarity with which northern European member states were helping those more affected by the situation; and pointed out the benefits that the European project had provided in the past, not only to Europe but to the wider international community. Finally, in terms of the third protective tool, Vale de Almeida and de Lecea also sought to tackle deep-rooted misperceptions about the EU in this regard, by emphasizing the sensibility of European economic logic and underlining EU members' solidarity over internal disputes.

Overall, this case study provides evidence that the EU actors showed adaptability to the situation and demonstrated a high-level of resolve to continue pursuing the goal of maintaining the image of EU integrity. They did this through emphasizing positive aspects of the EU's qualities and de-emphasizing the threats. Both leaders were deeply committed to tackling misperceptions in the United States about the Eurozone crisis, and also to correcting long-standing misunderstandings related to the EU, which had been ingrained in American society for some time. Commitment was visible, not only in the representatives' attitude, but also through their expressed conviction that the EU was not now part of the problem, but instead part of the solution. This became increasingly visible after the height of the crisis. At the end of 2013 and 2014, their speeches included frequent guarantees concerning the fulfilment of the TTIP and the EU's role in designing a new form of transatlantic global governance. They maintained a cohesive approach from within the EU Delegation and engaged in a constant and fluid dialogue with target audiences. Prioritizing certain interested audiences (predominantly academic and business communities) allowed them not only to deliver high-level facts and figures on what was happening in the EU in real time, but also to establish a point of first contact with publics who were more open to engagement and to maintaining a durable relationship. Although EU delegates fought an uphill battle when it came to media discourse, they continually updated their information regarding European Council and 'Troika' decisions, ${ }^{68}$ and sought to downplay the characterization of new controversies through the use of consistent narratives, data, and outreach that both foster good relationships in the future and preserve the idiosyncrasy of the EU identity.

Given this article's focus on just one aspect of EU public diplomacy in response to the Eurozone crisis, there are some limitations to this study. However, future research can begin to construct a more complete picture of the various tools used during this crisis and others to promote

\footnotetext{
${ }^{68}$ The term 'Troika' refers to the presence of the decision-making group of the European Commission, European Central
} Bank and International Monetary Fund. 
image resilience. Conclusions drawn from this case study alone might appear excessively positive, but the study's main goal was to show how protective tools were and could be put into practice. From a public diplomacy perspective, this was a suitable strategy for taking advantage of a crisis to improve a public image: that is, an 'image resilient' strategy.

An effective public diplomacy strategy seeks to build and rebuild a positive image that can withstand shocks, failures and crises. It is natural that when something goes wrong, an actor's image will take a hit. Engaging with influential audiences, listening to them and adapting to the circumstances of crisis all form the basis of crafting more positive perceptions that enable recovery from such setbacks. When the actor in question is an organization like the EU, it is important that public diplomacy strategies are coherent, take into account pre-existing public perceptions and are grounded in credible narratives. If it is clearly understood that crises involve both resilience and image resilience, crisis-response strategies can be mutually reinforcing.

Mai'a K. Davis Cross is the Edward W. Brooke Professor of Political Science at Northeastern University in Boston (United States) and Senior Researcher at the ARENA Centre for European Studies in Oslo (Norway). As well as over 30 articles and book chapters on a wide range of topics, she is the author of three books: The Politics of Crisis in Europe (New York: Cambridge University Press, 2017); Security Integration in Europe: How Knowledge-based Networks are Transforming the European Union (Ann Arbor, MI: University of Michigan Press, 2011); and The European Diplomatic Corps: Diplomats and International Cooperation from Westphalia to Maastricht (Basingstoke: Palgrave Macmillan, 2007). She holds a Ph.D. in Politics from Princeton University, and a Bachelor's degree in Government from Harvard University. She is also a term member of the Council on Foreign Relations.

María Teresa La Porte is Professor of International Communication at the University of Navarra (Spain) and Visiting Professor of Intercultural Communication at the Department of Communication Politique et Publique of the Universite Paris XII-Val de Marne (France). She was also Visiting Professor at the School of International Relations at the University of Southern California in 2009 and was distinguished with a Fulbright grant. Most of her research is related to analysis of international political news in the media and public diplomacy strategies. Her work is currently focused on the public diplomacy of non-state actors. 